\title{
Life-Threatening Upper Airway Compression: Quincke's Disease
}

\author{
Satvinder Singh Bakshi (D) \\ Mahatma Gandhi Medical College and Research Institute, Sri Balaji Vidyapeeth; Puducherry, India
}

Cite this article as: Satvinder Singh Bakshi. Life-Threatening Upper Airway Compression: Quincke's Disease. Eurasian J Emerg Med. 2018; 17 (4): 205-6.

\section{Clinical Image}

A 34-year-old man presented with sudden onset of dyspnea and throat pain for 2 hours. He had no clinical history of trauma, fever, or allergies and was consuming sea food when he developed the symptoms. There was no history of similar episodes in the past. Examination of the upper airway including the oropharynx revealed an enlarged, swollen, and congested uvula (Figure 1). The remaining physical and indirect laryngeal examination findings were normal and his vitals were stable. He was diagnosed with Quincke's disease was treated with dexamethasone and chlorpheniramine maleate. The patient's symptoms improved in 3 hours and he was discharged on oral cetrizine $10 \mathrm{mg}$ once a day for two days.

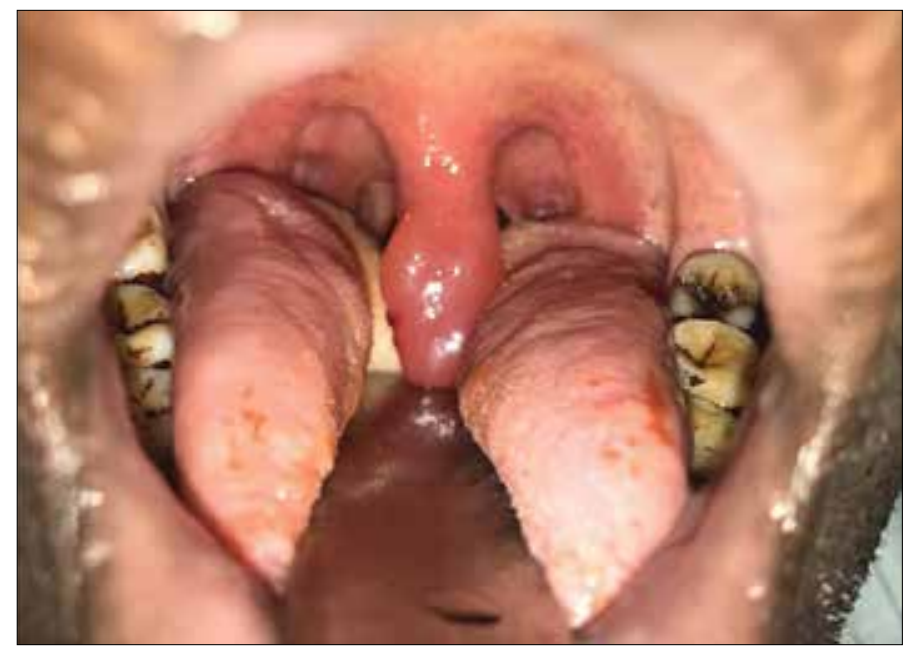

Figure 1. Patient with swollen and erythematous uvula
In 1882, Quincke first described isolated uvular angioedema. It is a relatively rare presentation of angioedema of the upper airway (1). Several causes have been implicated, such as trauma, hereditary angioedema, inhalation exposure, medication reactions, and infectious causes (2). Although rare, the uvular edema may cause obstructive respiratory distress and require immediate airway care. The treatment consists of intravenous $\mathrm{H} 1$ and $\mathrm{H} 2$ histamine blockers, corticosteroids, and rarely epinephrine $(1,2)$. Because of its potent anti-inflammatory properties and long half-life, dexamethasone is considered the medication of choice; however, for epinephrine has proven life-saving for emergency airway care injection. Recurrent attacks are observed in hereditary angioneurotic edema, which is caused by deficiency of the enzyme $\mathrm{C} 1$ esterase.

\section{Conclusion}

Quincke's disease or uvular edema is an uncommon presentation which can compromise the airway and lead to potentially a lifethreatening situation. The treatment includes the administration of antihistamines, corticosteroids, and epinephrine.

Informed Consent: Written informed consent was obtained from patient who participated in this study.

Peer-review: Externally peer-reviewed.

Conflict of Interest: The authors have no conflict of interest to declare.

Financial Disclosure: The authors declared that this study has received no financial support.

ORCID ID of the author: S.S.B. 0000-0003-4859-9588. 


\section{References}

1. Mattingly G, Rodu B, Alling R. Quincke's disease: Nonhereditary angioneurotic edema of the uvula. Oral Surg Oral Med Oral Pathol. 1993; 75:292-5. [CrossRef]
2. Yigit M, Sogut $\mathrm{O}$, Lisar H, Yigit E. Usefulness of $\mathrm{C} 1$ esterase inhibitor protei concentrate in the management of hereditary angioedema of oropharyngeal tissue. Niger J Clin Pract. 2018; 21: 531-3. 